\title{
Campesinos de la sal en el interior de al-Andalus. Las salinas de Guadalajara y Soria entre los siglos VIII al XII
}

\author{
Salt peasants in the interior of al-Andalus. The saltworks of \\ Guadalajara and Soria between the 8th and 12th centuries
}

Guillermo GARCÍA-CONTRERAS RUIZ

Author:

Guillermo García-Contreras Ruiz

Profesor Contratado Doctor. Departamento de Historia Medieval y Ciencias y Técnicas Historiográficas, Universidad de Granada (Granada, Spain)

garciacontreras@ugr.es

https://orcid.org/0000-0002-0655-7067

Date of reception: 11/04/21

Date of acceptance: 03/09/21

Citation:

García-Contreras Ruiz, G. (2021). Campesinos de la sal en el interior de al-Andalus. Las salinas de Guadalajara y Soria entre los siglos VIII al XII. Anales de la Universidad de Alicante. Historia Medieval, (22), 247-273.

https://doi.org/10.14198/medieval.19541

(c) 2021 Guillermo García-Contreras Ruiz

Licence: This work is licensed under a Creative Commons Attribution 4.0 International License (CC BY 4.0).

\section{RESUMEN}

El objetivo de este trabajo es analizar la organización social del territorio y la distribución de los asentamientos en relación con la gestión y control de los recursos naturales, especialmente la sal, a partir de los lugares donde se produjo su explotación: las salinas. Se proponen una serie de indicios que indican que fue esta una actividad que debemos considerar como agrícola, aunque la naturaleza de su producto sea mineral. El área geográfica objeto de estudio se localiza en el centro de la Península Ibérica, especialmente las zonas norte y este de la provincia de Guadalajara y el sur de la vecina provincia de Soria. En esta área hubo varias salinas de renombre, como Imón, La Olmeda, Riba de Saélices, Armallá o Esteras de Medinaceli entre otras. El marco cronológico abordado va entre los siglos VIII al XII. Desde el punto de vista histórico y cultural estos siglos corresponden al periodo en el que estas tierras fueron parte de la "Marca Media" de al-Andalus, el espacio central de la frontera entre la sociedad andalusí y la sociedad feudal de los reinos cristianos. Por ello se analiza desde la invasión e islamización de esta zona en los siglos VIII al IX, hasta la expansión, conquista y colonización que ocurrió durante los siglos XI al XII. PALABRAS CLAVE: salinas; al-Andalus; Marca Media; Arqueología del Paisaje; poblamiento medieval. 


\section{ABSTRACT}

The aim of this study is to analyze the social organization of the territory and the distribution of the settlements particularly in relation to the management and control of the natural resources, especially salt, considering the places connected with its production: the salt pans. Various arguments are proposed that hint towards to considered this activity as agricultural, although the nature of its product is mineral. The geographical area that has been chosen is located in the center of the Iberian Peninsula, especially the area north and east of the province of Guadalajara and south of the nearby province of Soria. In this area, there are various renowned saltworks areas, such as Imon, La Olmeda, Riba de Saelices, Armallá or Esteras de Medinaceli, among others. The chronological frame studied is the period from the 8 th to the 12 th century. From a historical and cultural point of view, these centuries correspond to the time in which this land was part of the "Marca Media" of alAndalus, that is, the central space of the frontier between the andalusi society and the feudal society of the Christian kingdoms. For this reason, it will be analyzed the invasion and Islamization of this area from the 8th to the 9th century, up until the expansion, conquest and colonization which occurred during the 11 th and 12 th centuries.

KEYWORDS: saltworks; Al-Andalus; Middle Mark; Landscape Archaeology; medieval settlement pattern.

\section{LOS CONDICIONANTES GEOGRÁFICOS E HISTÓRICOS QUE EXPLICAN LA IMPORTANCIA DE LAS SALINAS EN EL SECTOR ORIENTAL DEL CENTRO PE- NINSULAR}

En la parte norte y este de la actual provincia de Guadalajara, incluyendo también el sur de Soria, hay un grupo de importantes salinas históricas, alrededor de una veintena, de entre las que cabe destacar las de Imón, La Olmeda, Saélices, Medinaceli o Almallá entre otras. Todas ellas son salinas de interior que usan la salmuera subterránea que es sacada a la superficie y expuesta a la insolación solar para obtener el preciado mineral. Existe documentación escrita que menciona estas salinas con este sistema desde al menos los siglos XII-XIII, y durante toda la Baja Edad Media y la Edad Moderna (Espejo, 1918-1919; Altimir, 1946; Pastor, 1963; Gual, 1965; Ladero, 1987; Donderis, 2008; Ortego, 2013; García-Contreras, 2013; Rodríguez, 2015; Gismera, 2016) hasta llegar al siglo XIX y sobre todo hacia mediados del siglo XX cuando comenzaron a abandonarse (Plata, 2006; López de los Mozos, 2014). 


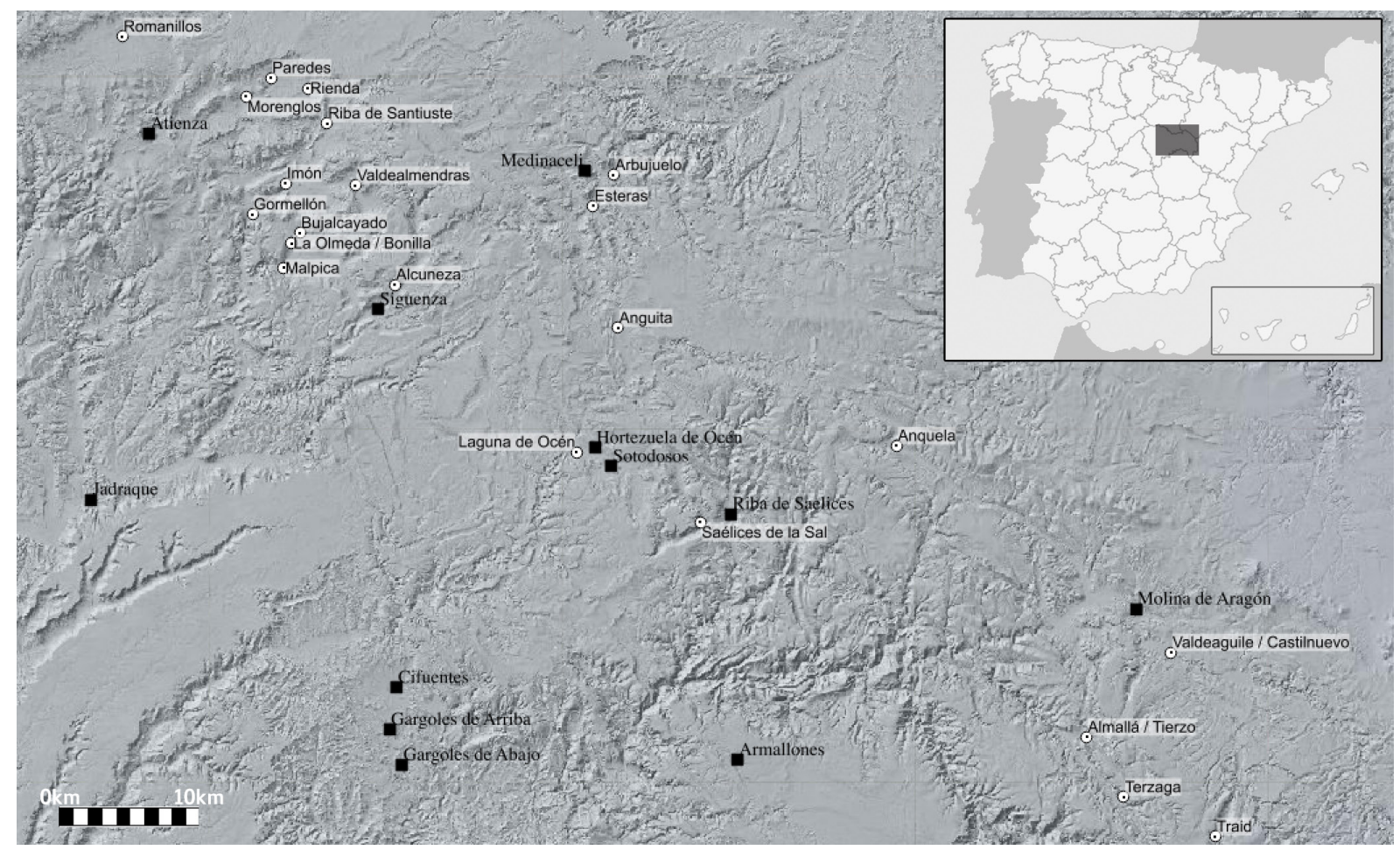

Fig. 1. Salinas y principales municipios localizados en el área de estudio. Elaboración del autor.

El elevado número de centros salineros de esta zona se debe a dos factores: 1) a los condicionantes geológicos e hidrológicos que permiten la obtención de sal de manera relativamente sencilla, y 2) a su localización geográfica en un encuentro de caminos en el límite donde es posible obtener sal en el interior de la Península Ibérica. En cuanto al primer factor, de manera muy general podemos decir que esta es una zona montañosa, entre el Sistema Central y el Sistema Ibérico, en la que los páramos, superficies montañosas aplanadas, son dominantes. Junto a ello, el principal elemento orográfico son los valles fluviales, siendo el más destacado el del río Henares, seguidos por los del río Salado, el Tajuña, el Gallo y el Tajo, a lo que podemos añadir el Jalón aún cuando pertenece a la actual provincia de Soria. La topografía de esta zona es bastante irregular, con alturas que van desde los 1300 metros de altura máxima, hasta los 600 metros en los fondos del valle, por donde discurren los ríos. Geológicamente, una de las principales características es la fuerte diferencia que hay entre las zonas elevadas y los fondos de valle. Los altos relieves están compuestos de materiales más duros, abundando las carniolas, las dolomías jurásicas y las calizas. El aspecto que presentan los montes, en la actualidad la mayoría sin vegetación o con manchas esporádicas de bosques de encinas y robles, es la de formas planas, con contornos simples y regulares y sin una excesiva pendiente, con una escasa capacidad para la agricultura por ser suelos pobres, estar expuestos a los condicionamientos climáticos, y por la escasa capacidad de retención de agua en superficie, ya que ésta se filtra. Frente a ello, en los amplios fondos de valle pre- 
dominan fundamentalmente las arcillas, que a veces contienen margas, yesos y por supuesto sales. Podríamos decir que la secuencia paisajística estándar, por lo tanto, es la de unas zonas altas de rocas de color gris, desnudas o salpicadas de bosques o praderas de hierba; desde las que se va descendiendo hacia las faldas de los montes, en donde abundan las surgencias de agua dulce y con ello la vegetación bosquiva, los arbustos y las plantas aromáticas; para finalmente llegar a unos rojos y arcillosos valles en donde el cultivo de cereal de secano es la práctica dominante (García-Quintana, 2008, pp. 52-53). Es importante destacar esos afloramientos de agua dulce en las medias laderas. Todos ellos aparecen en una especie de línea más o menos recta y horizontal que marca el cambio entre las zonas altas y los fondos del valle, y que se producen por ser el punto de contacto entre las dos diferentes litologías antes descritas. Aunque no son las únicas fuentes de agua dulce, sí son las mayoritarias, ya que en el fondo de los valles predominan las aguas saladas. Esto marcará en gran medida el poblamiento en la zona (García-Contreras, 2012).

En los fondos de valle descritos el acuífero subterráneo se carga de sales antes de salir a la superficie, originando manantiales de salmuera o endorreísmos y encharcamientos, que van a ser dominantes en gran parte del paisaje. Este mineral ha sido aprovechado desde época Prehistórica, bien de manera natural mediante su recolección o su aprovechamiento por parte del ganado, o bien con métodos cada vez más complejos hasta desembocar en las salinas (Malpica et alii, 2011). Éstas salinas son, básicamente, complejos hidráulicos en los que se extrae el agua salada mediante norias y se busca la saturación del mineral hasta convertirlo en grano al facilitar la evaporación del agua en balsas de poco fondo al calor y el viento. Lo que nos interesa destacar aquí es que este condicionante hidrogeológico de la salmuera y el endorreísmo en los fondos de valle no es positivo o negativo por sí mismo: dependiendo del modo en el que sea gestionado, puede ser un impedimento para el poblamiento, por las dificultades que imponen los encharcamientos salados a las comunicaciones y a la práctica agrícola; o un atractivo, por los beneficios económicos que genera un recurso natural tan preciado como era la sal cuando se crean las condiciones técnicas necesarias para su obtención, o cuando se usan de manera indirecta el ambiente de su entorno por su atractivo para la práctica ganadera o cinegética (García-Contreras, 2019a).

Señalábamos antes que había un segundo condicionante geográfico que explica, en parte, la importancia de las salinas de la provincia de Guadalajara. Se trata de su propia localización, casi en el límite de donde es posible obtener sal en el interior de la Península Ibérica (Carrasco y Hueso, 2008) ya que son relativamente escasos los lugares en toda la mitad norte y oeste donde la sal puede obtenerse, con excepción de las zonas costeras o las afamadas salinas de Añana (Álava), Poza de la Sal (Burgos) o Villafáfila (Zamora). Esto ha hecho que desde la Baja Edad Media el grupo de salinas de la provincia de Guadalajara llamadas «salinas de Atienza» hayan abas- 
tecido a casi toda la meseta norte, siendo determinante en el trazado de caminos y la localización de alfolíes, y siendo esa su importancia y, a la vez, muestra de su alta productividad (García-Contreras, 2021).

Como decíamos más arriba, en esta parte del centro peninsular se documentan alrededor de una veintena de salinas. Varias de ellas aparecen citadas en la documentación muy poco después de ser conquistadas estas tierras por Castilla en el proceso de avance feudal, como son la Olmeda (llamadas en la documentación medieval como Bonilla, Bonela, Boniella, Bonila...), Imón (mencionadas como Aimon, Emon, Aimonis...), Riba de Santiuste, Gormellón (localizadas cerca de Santiuste), las de Aguilar, que puede ser Aguilar de Anguita u otras cercanas a Castilnuevo, en territorio de Molina (Aguilé o Alguilé en los documentos), las de Terzaga o Terzaguilla, las de Traid y las de Armallá, cuyo topónimo (del árabe al-mallaha - salina) ya es de por si muy indicativo. A estas salinas se irán sumando menciones a otras en los documentos de los siglos XII y XIII: las de Anquela, Monsalud, Moratilla, Medinaceli... y ya a finales de la Edad Media, entre los siglos XIV y XVI, aparecerán referidas en los escritos casi todas las demás: Torremochuela, Alcuneza, Anquela, Morenglos (también llamadas de Alcolea de las Peñas), Tordelrábano, Rienda, Romanillos, Malpica (en Carabias), Valdealmendras, etc. Si no conocemos el nombre de muchas más, que las hubo, es porque a partir del s. XIV, la mayoría de estas salinas quedaron agrupadas bajo una sola denominación, las «salinas de Atienza», que incluía incluso

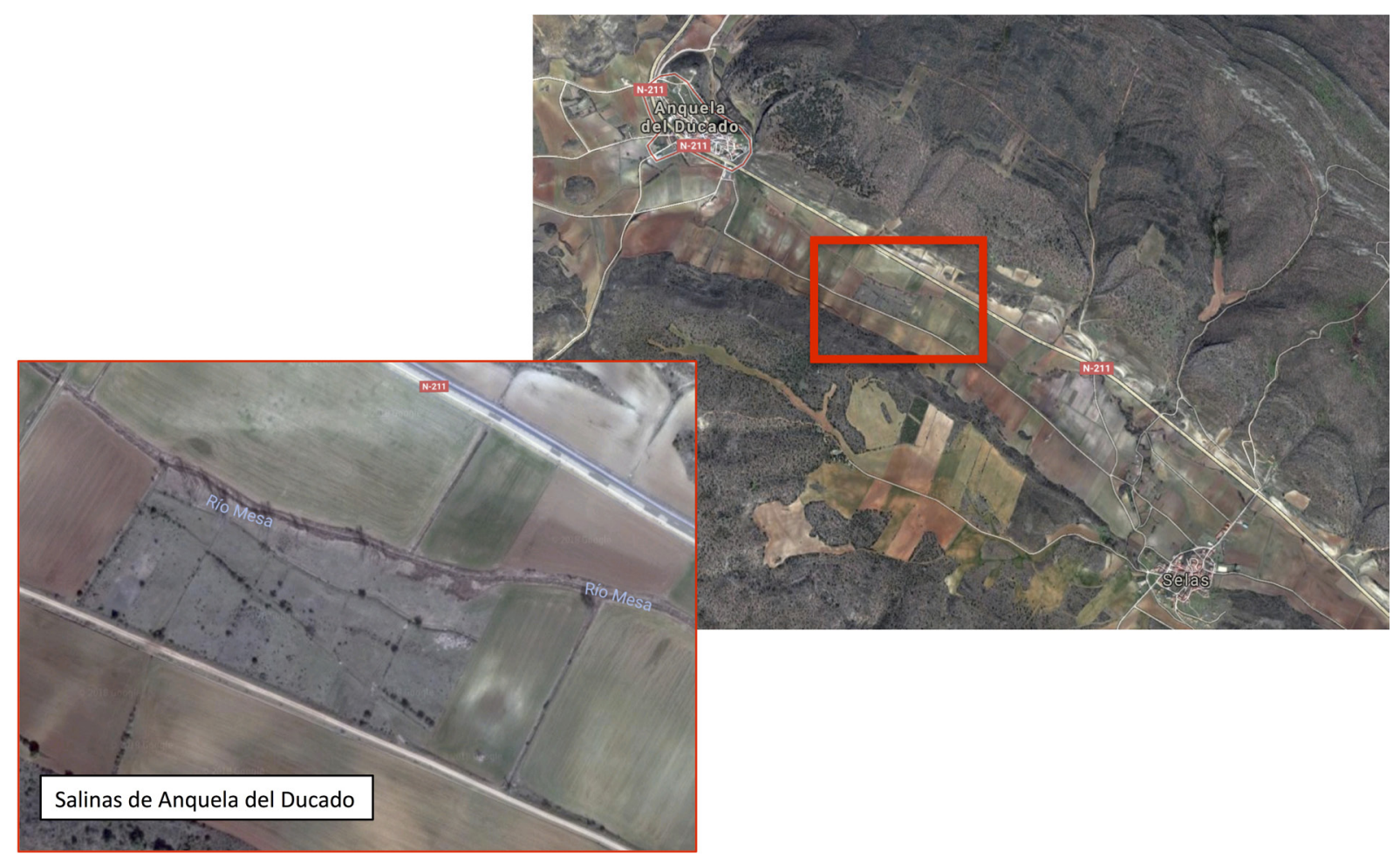

Fig. 2. Propuesta de localización de las desaparecidas salinas de Anquela. Imágenes capturadas del Google Maps. 
a las salinas situadas en Medinaceli, en la vecina provincia de Soria, que también aparecen desde el temprano siglo XII (Ladero, 1987; García-Contreras, 2013, 2021; Ortego, 2013; Gismera, 2016; García-Soto, 2006; García-Soto y Ferrero, 2007). En algunas cartografías antiguas, como el mapa de 1565 conservado en el Archivo de Simancas (A.G.S., M.P.D., 09, 096), aparecen todas las que conformaban las salinas de Atienza recogidas en un diagrama no cartográfico. Esto hace que en ocasiones sea difícil el estudio únicamente por fuentes documentales de cada centro en particular.

A esta dificultad debemos añadir un problema eminentemente arqueológico, relacionado con la cultura material: no hay evidencias materiales sobre las salinas de época medieval. De hecho, no hay evidencias materiales de salinas anteriores al siglo XVIII, o por lo menos no las conocemos aún. Ni en las distintas campañas de prospección acometidas en el valle del Salado ni en las del valle del Alto Tajo ni en el entorno de Medinaceli, por poner tres áreas vinculadas a estas «salinas de Atienza» (Malpica et alii, 2011; García-Contreras, 2013; Checa, 2014; Bueno, 2012), se han reconocido estructuras o restos materiales en las salinas existentes que puedan fecharse en los siglos en los que ya aparecen citadas en los documentos medievales. En cuanto a posibles restos en el subsuelo, en la provincia de Guadalajara sólo conocemos un caso de una salina que haya sido excavada. En concreto, la salina de San Juan, en Saélices de la Sal (García-Soto y Ferrero, 2006). Ni en la prospección del valle donde se ubican ni en la excavación arqueológica se documentaron restos anteriores al final de la Edad Media. Se hicieron sondeos en los edificios de las dos norias que tiene la salina, localizándose algunos restos de interés, como fragmentos de cerámica de arcaduces, vestigios de antiguas norias de madera, o algunas modificaciones arquitectónicas que se habían realizado en la puerta de entrada. Pero en ningún caso, restos anteriores al siglo XVIII. Y sin embargo, hay constancia documental de la existencia de las salinas que se remonta a 1203, y especialmente abundante a mediados del siglo XIV, y desde ahí en adelante (García-Soto y Ferrero, 2006; Ortego, 2013).

¿Qué ha ocurrido entonces? ¿Por qué no hay restos materiales anteriores al siglo XVIII? Esto mismo ocurre con el resto de salinas de la provincia de Guadalajara, tanto cuando se han estudiado las norias, como las balsas de evaporación o los alfolíes o almacenes. Creemos que es un problema que tiene que ver con la propia naturaleza de la explotación salinera a lo largo del tiempo, pero también con la forma de afrontar la investigación. Puede ser que la puesta en marcha de una arqueología de la producción, es decir el estudio estratigráfico de los espacios de trabajo, sea muy dificultosa de llevar a cabo ya que, siendo una infraestructura hidráulica, construida a base de mampuestos y madera (materiales que aguantan un ambiente extremadamente húmedo y salino) su vigencia hasta hoy en día ha requerido de un mantenimiento continuo (Quesada, 1995). Un mantenimiento que es resultado exclusivamente del continuo trabajo en ellas, de su limpieza y adecuación a unas 
necesidades de la producción que han ido variando a lo largo del tiempo. Es así que podemos distinguir entre lugares de éxito y lugares abandonados. Los primeros, a la hora de afrontar un estudio directo como el que se ha practicado en Saélices de la Sal, han recibido a lo largo del tiempo una serie de reformas entre las que se incluyen, en ocasiones, el rebaje de las tierras para alcanzar más cómodamente la salmuera de la capa freática. Y especialmente las zonas dónde se sitúan las norias. Noticias de estas reformas las hay desde la propia época medieval, por ejemplo en 1477 los Reyes Católicos ordenaron a Pedro de Robles reformar al menos 30 salinas englobadas como «las de Atienza» (Ortego, 2013, p. 212). Pero son sobre todo las llevadas a cabo en 1760 las que configuraron el aspecto que, grosso modo, ha llegado a nuestros días. En esa fecha Miguel de Muzquiz, Ministro de Hacienda de Carlos III, dio instrucciones para la reforma de numerosas salinas en el sector central de la Península, con el objetivo de alcanzar más fácilmente la capa freática para obtener la salmuera y poder expandir las salinas, con la creación de nuevos pozos, eras y canales, haciéndolas más productivas, y homogeneizando la arquitectura en todas las salinas reales (Meniz, 1988; López de los Mozos, 2014). Dan cuenta de estos planes de reforma borbónica los Planos de las Salinas de Imón y de La Olmeda de Jadraque

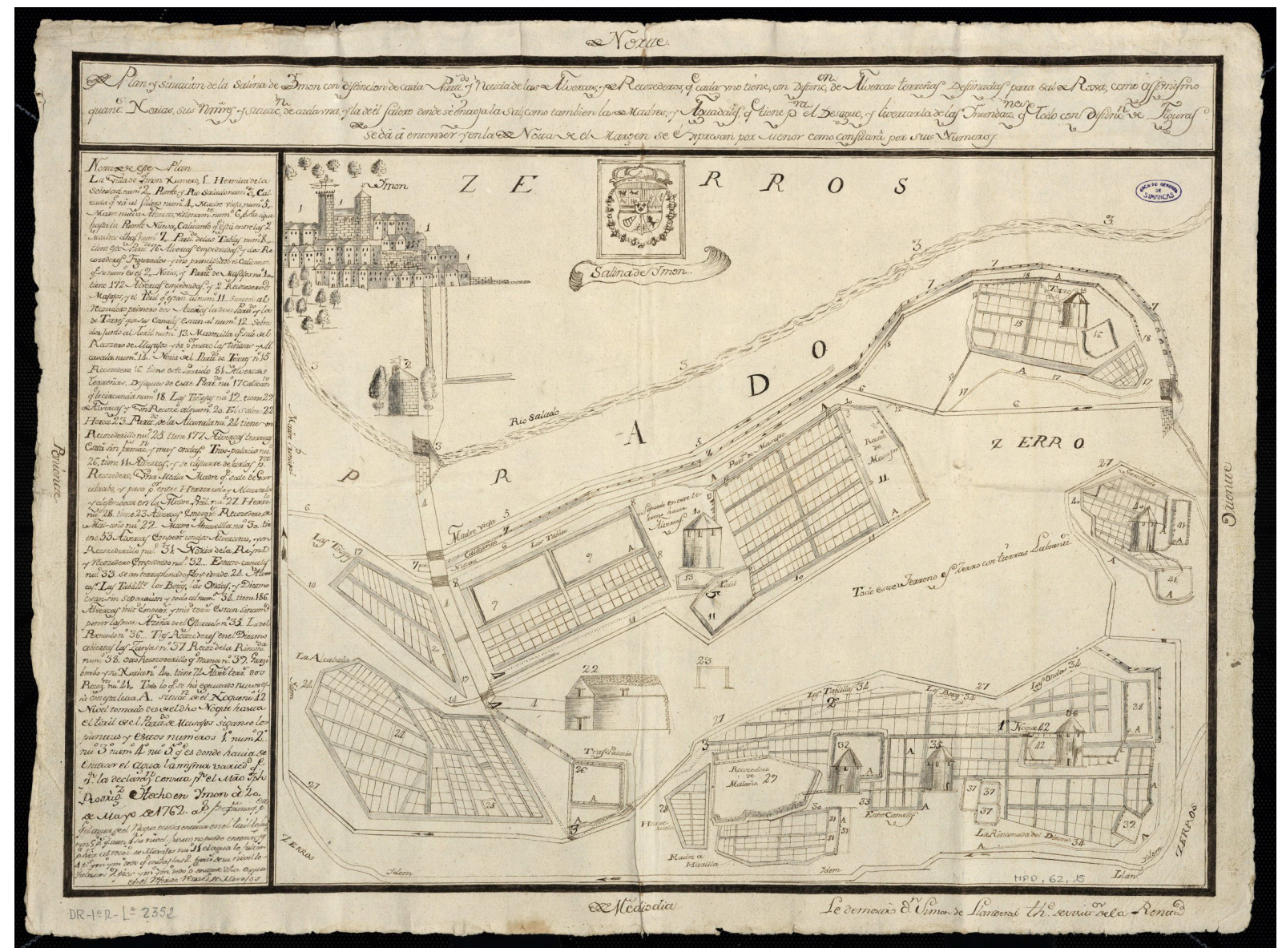

Fig. 3. Plano y situación de las salinas de Imon en 1762. Archivo General de Simancas (A.G.S., M.P.D., 62, 015) 


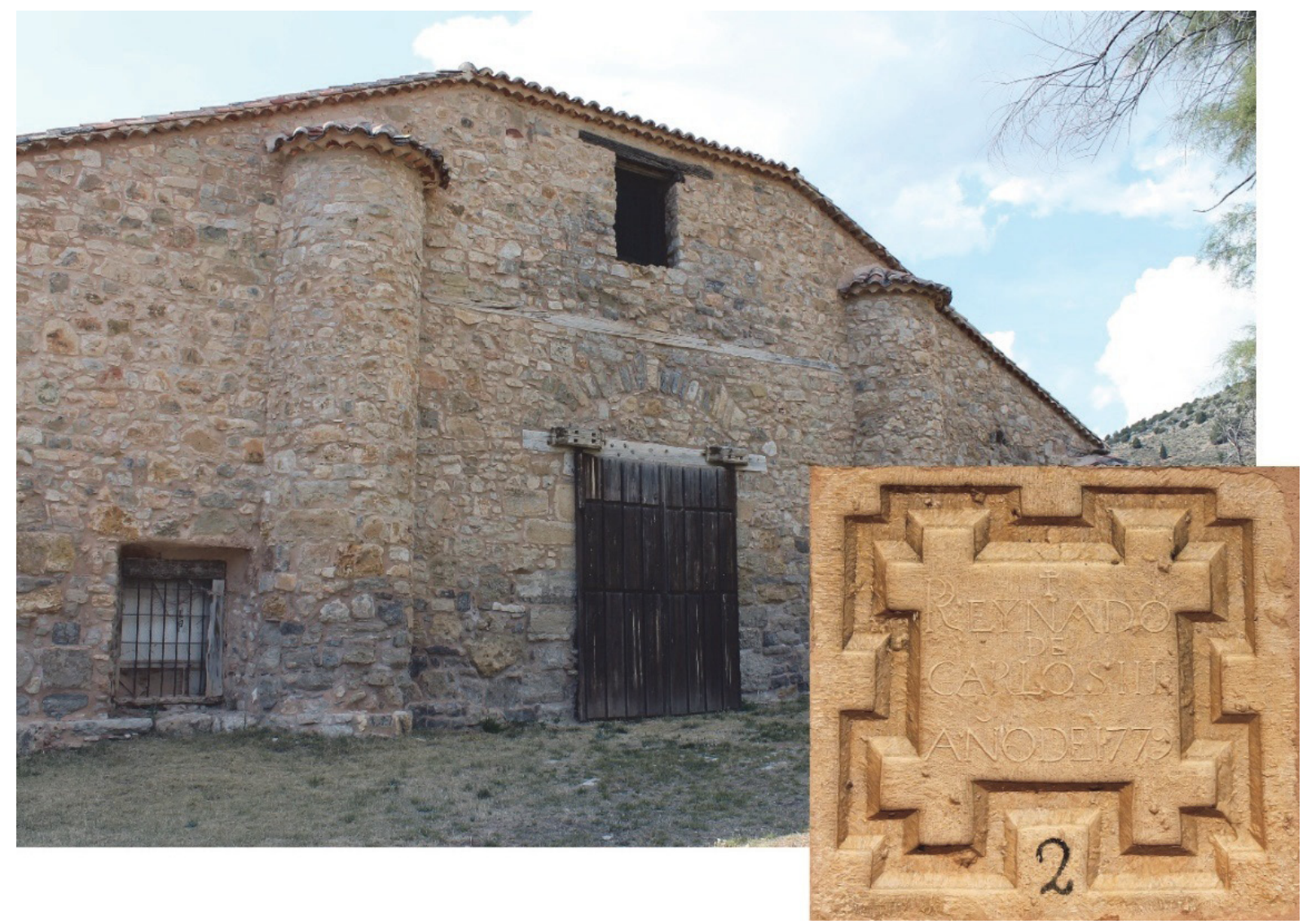

Fig. 4. Alfolí o almacén de sal en Almallá y placa que indica su fecha de inauguración.

Fotografías del autor.

de 1762 (A.G.S., M.P.D., 62, 015 y 016 respectivamente) o la inscripción que corona el almacén de las salinas de Almallá, en tierra de Molina, que lo data en 1779.

Es decir, una suma de obras en vertical y en horizontal desde finales de la Edad Media que presumiblemente han eliminado cualquier vestigio anterior. Cabría preguntarse si, a pesar de estas reformas, alguna de las balsas mantiene una estratigrafía más o menos original, pero no se ha intervenido en ninguna, que nosotros conozcamos. En cualquier caso, no es el único cambio, ya que también la reordenación de las balsas de evaporación, y por supuesto la progresiva maquinización de su infraestructura, sustituyendo norias y canales por motores de extracción y tubos de plástico. Además, hay que tener en cuenta otro hecho, en el caso del norte de Guadalajara: a finales del siglo XIX hay una revalorización de las salinas. Se crearon entonces grandes compañías explotadoras, como la Sociedad «Salinas de Imón y la Olmeda», constituida en 1873, que controlaba las dos explotaciones más productivas de la provincia de Guadalajara. En otros casos, en la mayoría de hecho, será un único propietario particular el que se haga cargo de las explotaciones. Y además, se iniciaron nuevas explotaciones salineras por toda la provincia, y sobre todo en el territorio que nosotros estudiamos. Éstas se beneficiaron tanto del desestanco de 
la sal como de otros factores tales como el auge de las minas de Hiendelaencina, en donde se usaban grandes cantidades de sal como consecuencia del sistema de «beneficio» de la plata (García-Soto, 2006; García-Soto y Ferrero, 2007). Lo que no sabemos, dada la ausencia de estudios específicos y las alteraciones que se llevaron a cabo en estos momentos, es si estas salinas que ahora adquieren carta de nacimiento son explotaciones anteriores. En este sentido, valga solo un ejemplo: las salinas de Valdealmendras, oficializadas en torno a 1889-1890 (García-Soto, 2006, pp. 24-25) son mencionadas, sin embargo, en dos ocasiones a principios del siglo XVI como salinas que estaban a punto de desaparecer, primero en 1517 (Colón, 1988) y luego en 1550 (Minguella: 1912, p. 241), por lo que eran de fecha aún anterior, siendo muy probablemente las que se citan en 1262 como «Valdamentas» (Bueno, 2009, p. 372). Es sólo un ejemplo de una salina, probablemente de origen medieval, sobre las que no conocemos nada hasta que ponen en funcionamiento oficialmente a finales del siglo XIX, en espacios que debemos considerar de éxito histórico, quizás por el buen emplazamiento para la obtención de la sal (García-Soto, 2006; García-Soto y Ferrero, 2007; y Gismera, 2016).

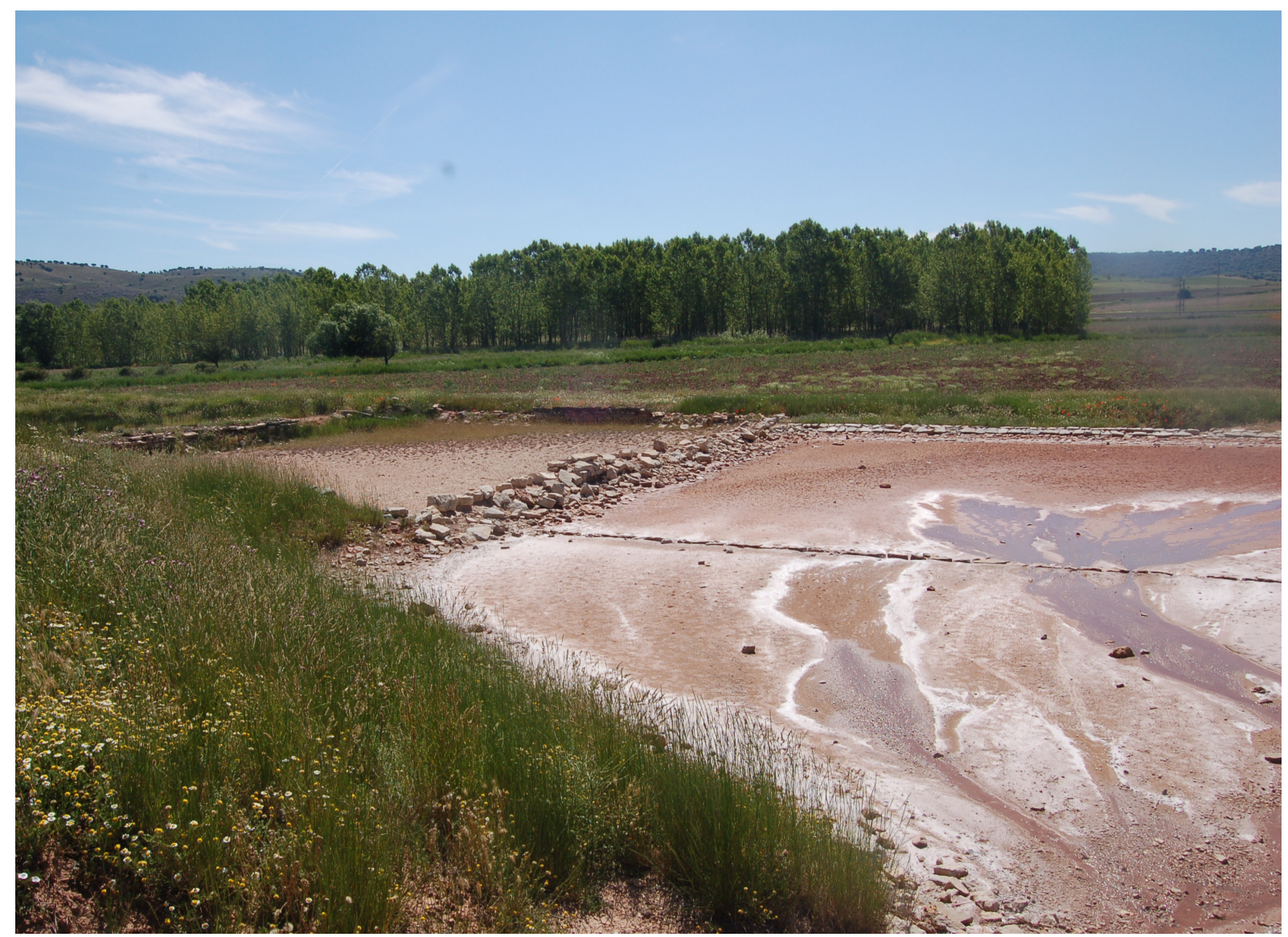

Fig. 5. Salinas de Alcuneza en proceso de desaparición al ser invadidas por la vegetación tras su abandono, en las que casi de manera natural sigue concentrándose la sal en verano. Fotografía del autor, septiembre 2010. 
En todos estos casos de salinas de éxito, y a menos que la arquitectura de las balsas de evaporación pueda mostrar una cierta diacronía como ocurre en las salinas de Añana en el País Vasco (Plata, 2003) o que hayan quedado restos de su antigua tecnología atribuida a los musulmanes (Cruz, 1989; Quesada, 1995), su estudio difícilmente puede realizarse mediante una excavación arqueológica convencional, ya que los datos más antiguos que se aportarán serán los de la última gran renovación de la primera época borbónica, como veíamos en el caso de la Salina de San Juán en Riba de Saélices. Habrá entonces que acudir a otras formas de aproximación arqueológica, sea a partir de la microtoponimia de las balsas y eras de evaporación, sea por la topografía y distribución de los subconjuntos en los que puede dividirse un conjunto salinero (pozo-balsa-eras de evaporación-canales de distribución), o sea por análisis paleoambientales indirectos que, en el caso del área estudiada, no han sido realizados hasta ahora. Además, en algunos casos, la propia organización interna de las salinas permite entrever una cierta evolución, sobre todo en las más grandes. Así, la existencia de partidos diferenciados cada uno con su propia noria y sus albercas, o la cierta alineación o desorden que algunos conjuntos puedan tener respecto a los demás, pueden ser indicativos. Y evidentemente, por la lectura con óptica de arqueólogo de la documentación escrita.

También los espacios salineros abandonados han sufrido también una serie de afectaciones, tanto antrópicas como naturales, que han supuesto su cubrición por arcillas y depósitos sedimentarios, cuando no desprendimientos de farallones rocosos próximos, lo que ha conllevado la desaparición de sus canales; la invasión por parte de la vegetación, sea natural o sea los campos de cultivo, de sus balsas; cuando no directamente la desecación de estos espacios para facilitar actividades agrícolas o ganaderas. Quizá estos casos permitan, en un futuro, ser abordados mediante una excavación, siempre y cuando tengamos constancia de que su abandono se produjo sin haber sido afectadas por las grandes reformas borbónicas.

En cualquier caso, sean espacios de éxito hasta el presente, abandonados o en proceso de abandono en el momento de su estudio, quizás el tipo de estudios que se puede acometer con mejores perspectivas de aportar una información histórica relevante sean aquellos que pretendan integrar el estudio de las salinas en relación con el resto de elementos que estructuran y contextualizan tanto el poblamiento (castillos, aldeas, caminos, torres...) como la producción, sea campesina o centralizada (agricultura, ganadería, minería...). Es decir, dentro de un estudio complejo y holístico que podemos denominar como Arqueología del Paisaje (Malpica, 2008; García-Contreras, 2016). 


\section{EL PERIODO ANDALUSí EN EL SECTOR ORIENTAL DEL CENTRO DE LA PENÍNSULA IBÉRICA}

Desde el 711 el territorio que estudiamos será conquistado e islamizado, formando parte de la zona de asentamiento de distintos grupos beréberes. A partir del siglo X, con la instalación del califato en al-Andalus y la expansión de los reinos feudales hasta el valle del Duero, esta zona será frontera directa entre musulmanes y cristianos, siendo numerosos los enfrentamientos y actividades bélicas momento en el que pasa a denominarse Marca o Frontera Media. Durante el siglo XI no está claro a quien pertenecieron estas tierras, ya que se sucedieron conquistas cristianas, sobre todo el reino de Castilla, y de los reinos taifas de Zaragoza y Toledo, para pasar definitivamente desde el siglo XII a formar parte de la corona de Castilla. Es decir, el periodo andalusí que estudiamos abarca desde el siglo VIII hasta el siglo XII.

Desde hace tiempo se ha detectado que el poblamiento andalusí del norte de la provincia de Guadalajara y el sur de la provincia de Soria carece del volumen de trabajos que hay para otras partes de la Marca Media, algo que se arrastra desde hace más de treinta años (Zozaya, 1991). Ha habido algunos esfuerzos por sistematizar, catalogar y clasificar tanto los distintos yacimientos como las dispersas referencias documentales que pueden usarse para analizar este periodo (Morère, 1983; Pavón, 1984; Retuerce, 1994; García-Soto, 2005). Pero espacialmente importante es la ausencia de intervenciones arqueológicas, más allá de algunas prospecciones y de algunas excavaciones. Algo que en otras regiones de la Marca Media de al-Andalus se está solventando en los últimos años (algunos ejemplos son Chavarría, 1997; García, 2007; Gillote, 2008). Esto ha hecho también que se haya integrado el estudio de esta zona del centro peninsular dentro de marcos interpretativos más amplios referidos al conjunto de la frontera de al-Andalus.

Por lo general, y dejando a un lado las más antiguas visiones de todo este área como despoblada y dedicada sólo a la defensa de la frontera (Herrera, 1985), desde hace ya varias décadas se tiende a interpretar que todas las fortalezas que se extendían desde el río Manzanares (Madrid) al valle del Jalón (Soria), y desde el Sistema central a la frontera con la actual provincia de Cuenca, obedecían a una doble frontera, aquella principal contra el avance de los reinos cristianos, y una frontera interior orientada a preservar el territorio tanto de las agresiones procedentes de clanes beréberes desde el norte y el este, como de Toledo (Manzano, 1991). Parece ser que las constantes revueltas toledanas y de la región de Santaver obligaron a los omeyas, apoyándose en grupos beréberes, los Banū Salīm en particular, a intentar crear una especie de red militar que rodeaba a la insumisa sede de la antigua capital visigoda, cuyos habitantes, bien sea por motivos fiscales bien sea por motivos administrativos, mostraron a lo largo de todo el tiempo una fuerte oposición frente al poder central. Se ha propuesto que esta situación obligó a crear un limes interno, cuyo puntos fuertes eran Madrid, Calatalifa, Uceda, Calatrava, Olmos y Canales (Zozaya, 2004), 
además de Alcalá de Henares, Guadalajara, Peñafora e incluso otros que quedan más al Este hasta llegar a Medinaceli, territorio objeto de nuestra atención.

Otra línea de interpretación destaca una fuerte impronta del carácter beréber de este territorio a partir de las menciones al control por parte de un grupo de norteafricanos, la familia de los Banū Salīm (De Felipe, 1997, pp. 220-224; Bueno, 2015; García-Contreras, 2019b). Su distribución se relaciona con la aparición de una serie de formas cerámicas determinadas (Bermejo y Muñoz, 1996; Bermejo y Muñoz, 1999). Estas formas cerámicas presentarían un área de dispersión muy concreta por lo que deben de proceder de alfares locales, vinculados a un grupo humano concreto, esa familia beréber (De la Granja, 1966, p. 492). Más o menos es la misma línea interpretativa propuesta para comprender la construcción y funcionalidad de algunas torres de la Marca Media (Almagro, 1976). Aunque sugerente, esta interpretación tiene el problema, llevada al extremo, de explicar a partir de consideraciones casi raciales acontecimientos históricos o cualquier resto material distintivo del período y la zona, sin examinar las específicas condiciones ecológicas, económicas y sociales (Jiménez, 1995; García-Contreras 2019b). Es cierto que toda la zona montañosa comprendida entre las provincias de Cuenca, Teruel, Guadalajara y Soria, grosso modo la parte central y oriental de la Marca Media, constituyen uno de los núcleos más importantes de población beréber de al-Andalus, y que los textos de la época nos informan de cómo muchos de los aspectos políticos, sociales y militares tienen como trasfondo la distinción entre norteafricanos y árabes. Pero es poco probable que la explicación de todo lo ocurrido esté sólo en el carácter beréber de la población que habitó estas tierras. Además, sin saber cuantitativamente ni cualitativamente su relevancia.

Más allá de la posible identificación de poblaciones bereberes, la única certeza que tenemos es que hay un buen número de asentamientos cuya cultura material se puede fechar en época andalusí (García-Contreras 2020), y que la mayor parte de los que conocemos corresponden a asentamientos en altura, castillos y torres. Son los mejor conocidos gracias a su mejor conservación, pese a reocupaciones y reutilizaciones posteriores, y a que son los que en primer lugar han llamado la atención de los investigadores. Pero no son los únicos tipos de asentamientos que hay. Aunque es muy difícil identificarlos mediante prospecciones como las llevadas a cabo (García-Contreras, 2013), hemos encontrado algunos asentamientos que podemos considerar aldeas o alquerías, situados mayormente en las medias laderas junto a las surgencias de agua dulce mencionadas al principio de este trabajo. Pensamos que estos son, realmente, los espacios en los que debemos fijar nuestra atención para que la imagen que tenemos sobre el poblamiento tenga más sentido que el de la simple línea maginot conformada por castillos y torres de filiación beréber.

Lo que sí parece claro es que, a falta de proyectos de excavación arqueológica, la única salida que hay para dar un paso adelante en el conocimiento que tenemos 
sobre el poblamiento medieval es la de revisar los datos ya existentes, pero desde una óptica diferente, más acorde con el tipo de investigaciones que se están planteando en el resto del territorio andalusí.

\section{LA EXPLOTACIÓN DE LA SAL EN ÉPOCA ANDALUSÍ. ¿CONTROL CAMPESINO?}

En la primera época andalusí, desde los siglos VIII y IX se irá transformando el paisaje altomedieval hasta configurarse en el siglo $\mathrm{X}$ un patrón de poblamiento relacionado con la explotación de los recursos naturales bastante diferente al del periodo anterior (Olmo, 2011; García-Contreras, 2016). Este poblamiento vendrá marcado por la existencia de cinco tipos de asentamientos: las ciudades, las torres y algunas cuevas, que no abordaremos en este trabajo, los asentamientos en altura y los núcleos rurales tipo aldea o alquería. Lo primero que llama la atención al analizar la localización de estos dos últimos tipos de asentamientos es su alejamiento de las partes llanas, de los fondos de valle, marcado edafológicamente por la existencia de suelos de rendsinas y margas irisadas (liásivas) yesíferas, asociadas a suelos con alto contenido en sales (Alonso, 1978, p. 240), pero que permiten un intenso aprovechamiento agrícola a base de cereales y leguminosas, dada su capacidad para retener la humedad, y que fue mayormente explotado en épocas romanas y visigodas. En lugar de ocupar estos fondos de valle, la mayoría de los asentamientos rurales, y por lo tanto aquellos directamente relacionados con los espacios de trabajo agrícolas y salineros, se sitúan en las medias laderas de los cerros y sierras, junto a las abundantes surgencias de agua dulce existentes. El patrón de asentamiento rural ahora parece responder a un modelo político descentralizado, y topográficamente dual (García-Contreras, 2015, 2016, 2018a; Malpica et alii, 2011; Lázaro, 1995; Retuerce, 1995; Olmo, 2002 y 2011; García-Soto, Ferrero y Guillén, 2004; Bueno, 2012, 2015; Checa, 2014). Por un lado los asentamientos en altura fortificados, que responden a condicionamientos sociopolíticos en los que no vamos a entrar ahora y por otro los asentamientos a media ladera, más ligados a la explotación directa de los recursos naturales Se trata de pequeñas aldeas, que debemos considera como las alquerías andalusíes, asociadas a los lugares de contacto entre las distintas litologías: por encima se sitúan las calizas y dolomías, que debido a su bajo espesor y su baja fertilidad no consienten una agricultura suficiente para abastecer a la población, pero sí una cabaña ganadera que podría alternar estas zonas de monte con los prados halófilos situados en el llano. En esas zonas de monte, desde la Edad Media se produce una sobreexplotación, no sólo por las actividades ganaderas sino también por la extracción de la madera, que ha cambiado su fisonomía (Fidalgo, 1987, pp. 25-28). En la misma cota en la que se sitúan esas aldeas o alquerías y las surgencias de agua, junto a ellas o inmediatamente por debajo cuando el endorreísmo de los fondos de valle lo permite, se han localizado algunas terrazas, fosilizadas o bien hoy en cultivo, con 
acequias que distribuyen el agua entre las parcelas que pueden estar remitiéndonos al sistema agrícola del periodo (García-Contreras, 2018b). Estas tierras se benefician de la sedimentación resultante de la erosión de las partes altas de los montes, mezclado con las arcillas del fondo del valle, que dan como resultado zonas de suelos blandos y menos permeables óptimas para la agricultura (Hernando, 1977).

Respecto a los asentamientos en altura, puestos de control del territorio la mayoría de los cuales presentan evidencias de fortificación cuando no son castillos directamente, se sitúan en cerros aislados o promontorios rocosos que desde las parameras se adentran en el valle. Parece haber una preferencia por las zonas de areniscas, quizás por la facilidad que presentan para ser trabajadas. Además, es la roca más utilizada en la construcción de estas fortificaciones. Estos castillos se sitúan en suelos rocosos, poco desarrollados, asociados a litosuelos, calizas, muy pobres en nutrientes y con una escasa potencia de retención hidráulica, en cuyo entorno no puede cultivarse, debiendo sus habitantes bajar a trabajar al llano o ser abastecidos por la producción de las aldeas o alquerías.

Varios asentamientos andalusíes, tanto aquellos en altura como los otros que consideramos rurales, están relacionados directamente con alguna de las salinas que aparecen en la documentación escrita por primera vez pocos meses después de la conquista castellana de estas tierras, en torno al siglo XII, y que se localizan en los fondos de valle donde el endorreísmo salino o hipersalino es más acusado. De hecho, son los asentamientos andalusíes los que encontramos más cercanos a estas salinas, más que ningún otro que pueda fecharse en ningún otro periodo histórico, al menos por los materiales que conocemos en superficie. Podemos mencionar varios ejemplos en el valle del Salado: las salinas de Riba de Santiuste, localizadas entre el castillo de la Riba y el asentamiento rural de Torrequebrada, ambos con dataciones andalusíes (García-Contreras, 2018a); lo mismo en el caso de las salinas de Imón, con otro asentamiento andalusí en la media ladera del cerro que queda al Sur; y algo similar en el caso de las salinas de La Olmeda de Jadraque, denominadas Bonilla en la documentación medieval más temprana como ya se ha dicho, nombre con el que hemos bautizado al asentamiento andalusí localizado en la media ladera de la sierra que delimita la propia salina por su lado occidental (García-Contreras, 2016).

Esto que se ha documentado en el valle del Salado es lo mismo que puede verse en la zona del Alto Tajo, concretamente en el valle del río Bullones, donde están las salinas de Armallá al pie del cerro en el que se ubica el asentamiento del castillo de los Moros datado al menos en el siglo X así como otros de igual cronología andalusí como Fuente del Barranco o Fuentejimena, todos ellos entre Tierzo y Terzaga, que pudieran estar en relación con las salinas de Terceguella o Tercezuela (Lázaro, 1995; Arenas y Martínez, 1999: 210; Olmo, 2002, p. 482; Checa, 2014, pp. 76-77; GarcíaContreras, 2016). 


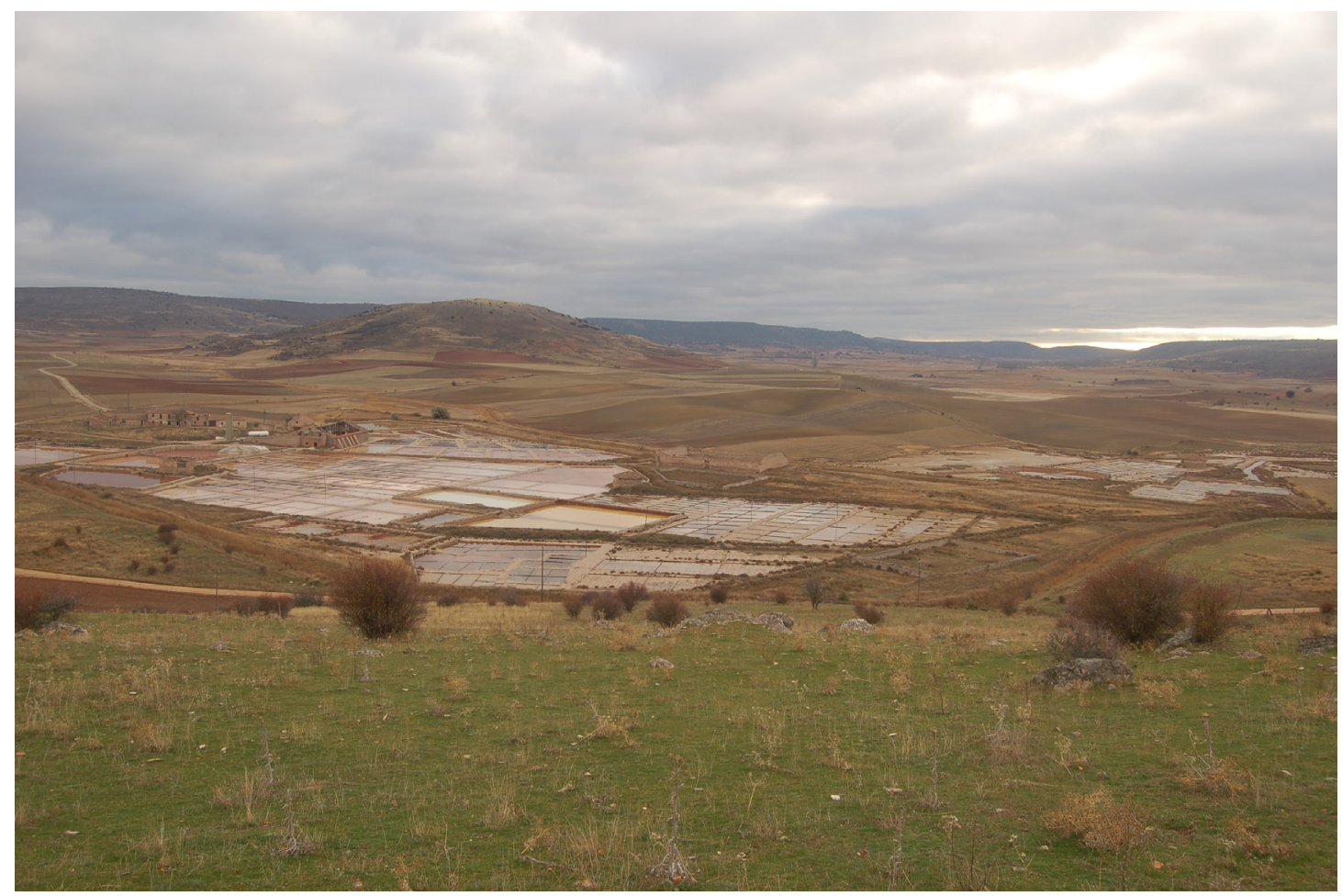

Fig. 6. Salinas de La Olmeda de Jadraque vistas desde el asentamiento andalusí de Bonilla. Fotografía del autor, septiembre de 2010.

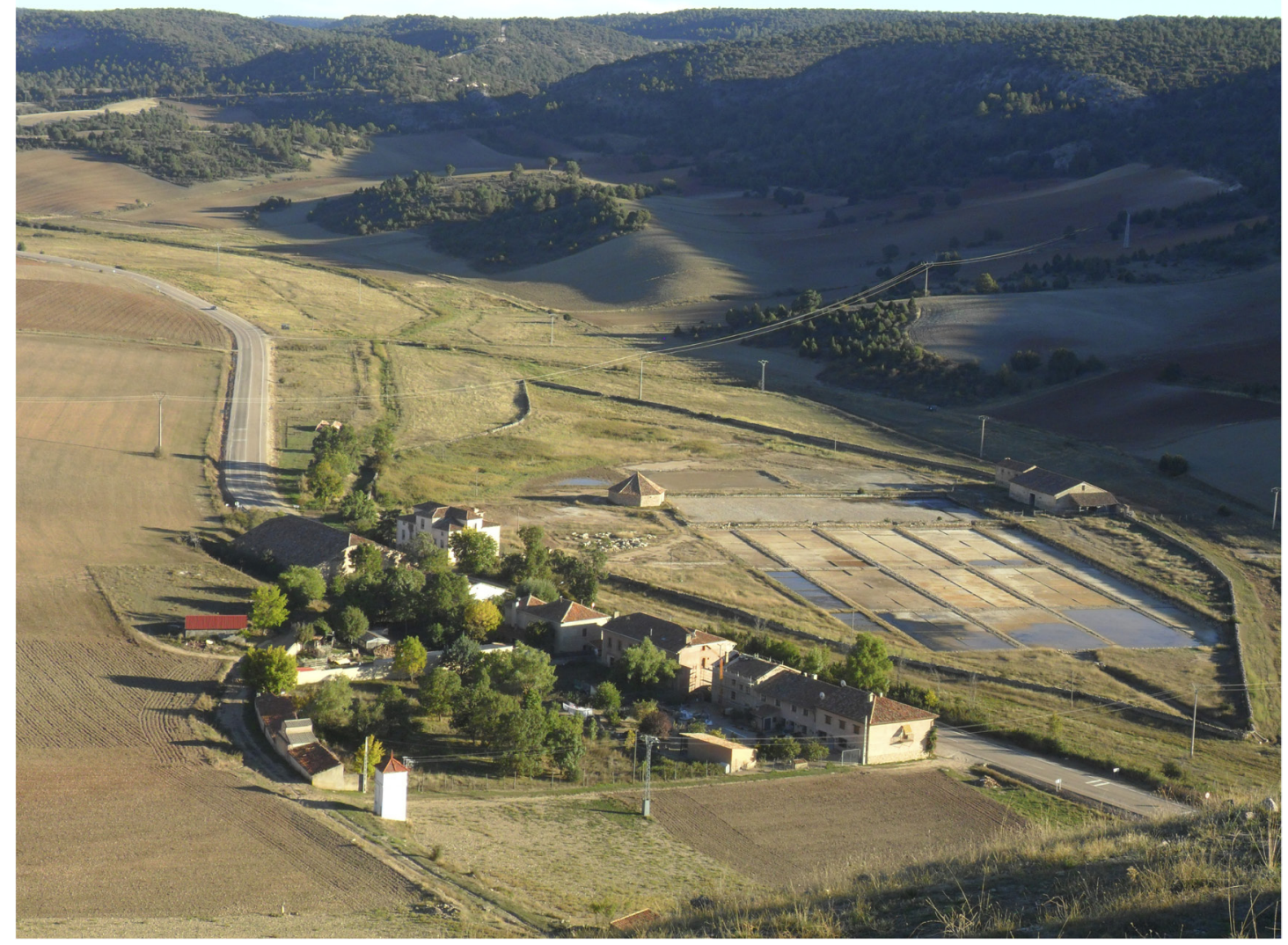

Fig. 7. Salinas de Armallá vistas desde lo alto del asentamiento andalusí del Castillo de los Moros, al sur de Tierzo. Fotografía del autor, septiembre 2018. 
También al sur de Molina, en Castilnuevo, más concretamente en Valdeaguilé donde hay salinas desde el siglo XII (Minguella, 1910, p. 424) y donde se ha documentado un asentamiento rural andalusí e incluso una pequeña fortificación que quizás sea anterior a la propia Molina de Aragón (Fabián, 2012, p. 73). Y de nuevo, esta misma relación entre asentamientos andalusíes y salinas mencionadas en la documentación medieval más temprana vuelve a repetirse en el entorno de la vecina Medinaceli, en los valles de los arroyos y tributarios del río Jalón, donde por ejemplo hay un área salina entre el castillo de Esteras de Medinaceli y el asentamiento rural de La Mantilla, ambos con dataciones andalusíes; o algo más al norte en el arroyo del Pradejón donde las salinas del Arbujuelo están a los pies del cerro en el que se localiza otra de estas alquerías (Bueno, 2012; García-Contreras, 2016).

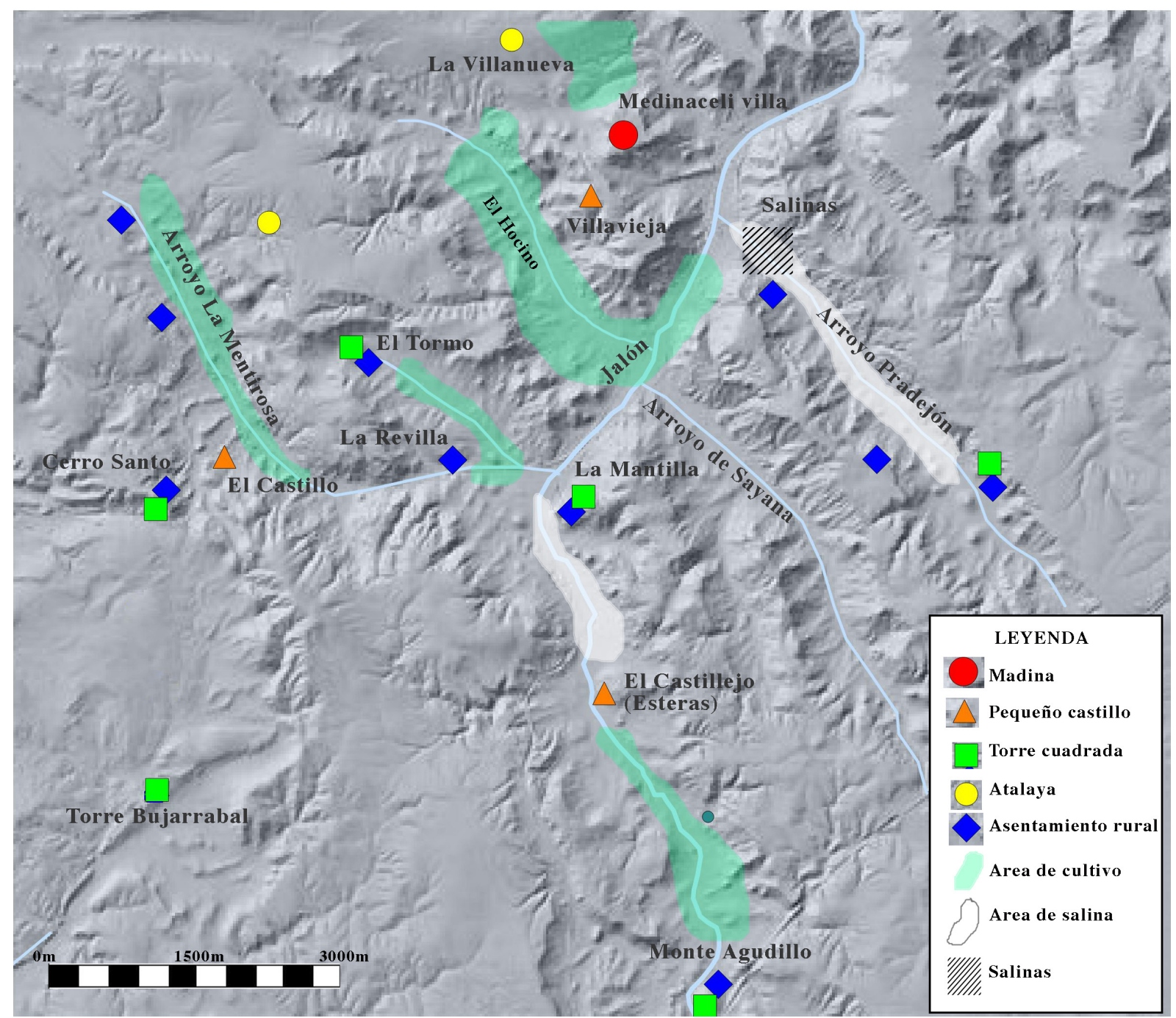

Fig. 8. Distribución del poblamiento andalusí en el entorno de Medinaceli en relación con los espacios de cultivo y los salineros (mapa de García-Contreras, 2016 modificando el original de Bueno, 2012). 
En otros casos la relación de los asentamientos andalusíes es algo más incierta, aunque apunta en la misma dirección. De nuevo refiriéndonos al valle del Salado, las denominadas salinas del Gormellón están a menos de un kilómetro del complejo asentamiento andalusí de Santamera que consta de un espacio en altura y de otro encajonado en un farallón rocoso de la hoz del río Salado (García-Contreras, 2015, p. 66). En el caso del valle del Alto Tajuña tenemos tres interesantes casos. El primero es el de las ya mencionadas salinas de San Juán, cercanas a Riba de Saélices pero en un valle diferente de aquel otro en el que se localiza el poblado a media ladera de Los Casares que consta de cueva y torre (García-Soto, Ferrero y Guillén, 2004), mediando entre ambas una distancia de cerca de $5 \mathrm{~km}$. El segundo caso es el de las salinas de Aguilar de Anguita, que pudieran ser las que se mencionan en 1168 como «salinis de Alguile» (Minguella, 1910, p. 424), aunque hay dudas sobre si esta cita refiere a las salinas de Castilnuevo-Valdeaguilé que mencionábamos antes) y que se localizan no lejanas de dos asentamientos con evidencias cerámicas de época andalusí, el de Benamira y el de Aguilar, este último además citado en el siglo XI en el Poema del Mio Cid y que consta de cueva y torre fechada en época andalusí (García-Contreras, 2016, pp. 376-377). El tercer caso, algo más al sur del anterior pero también en valle del Alto Tajuña, es el del entorno del municipio de Hortezuela de Océn donde se ubica la laguna de Océn, una formación endorreica salina en el fondo

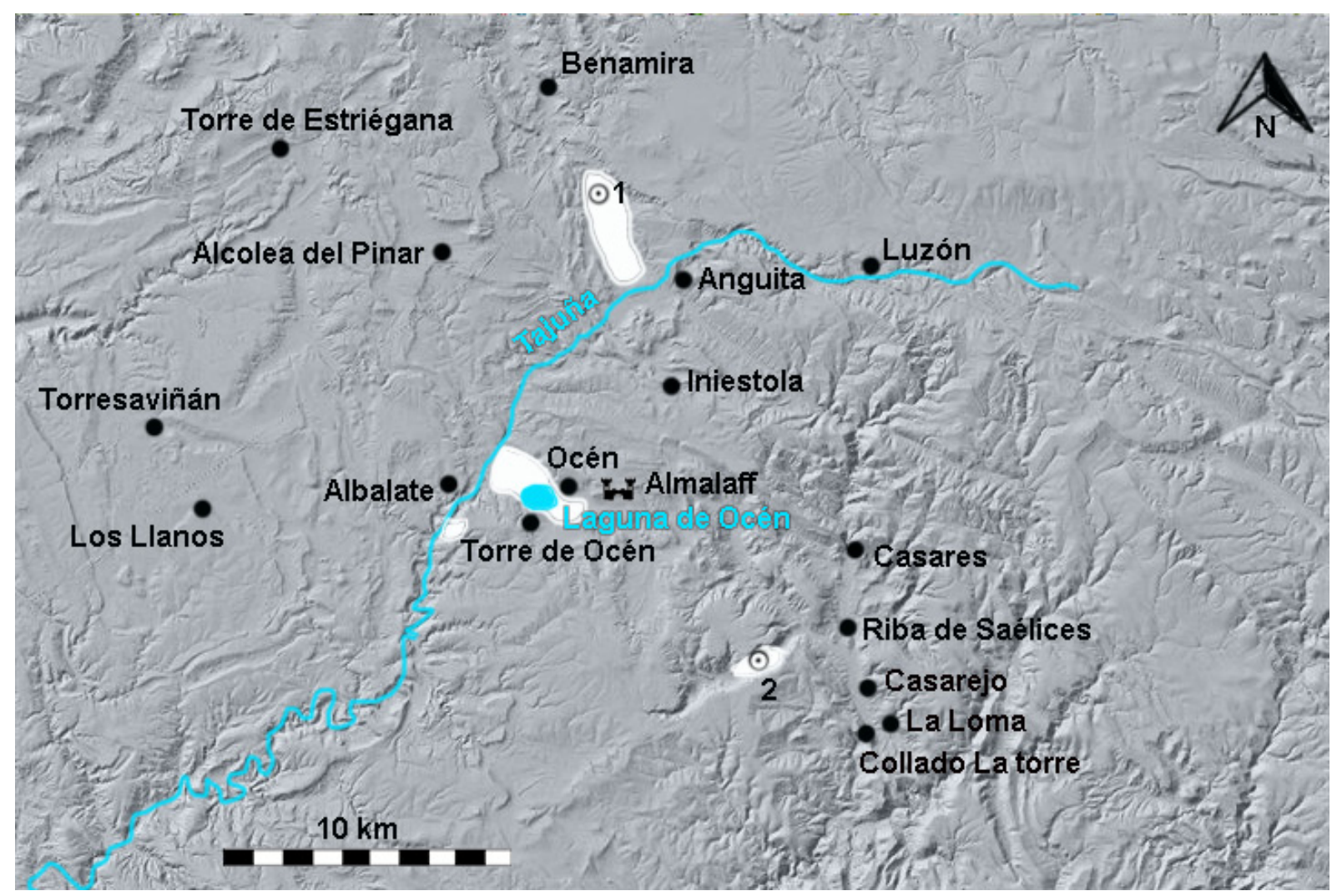

Fig. 9. Poblamiento y topónimos andalusíes en el alto valle del Tajuña y el entorno de la Laguna de Océn, indicando la localización del castillo de Almalaff. Elaboración del autor. 


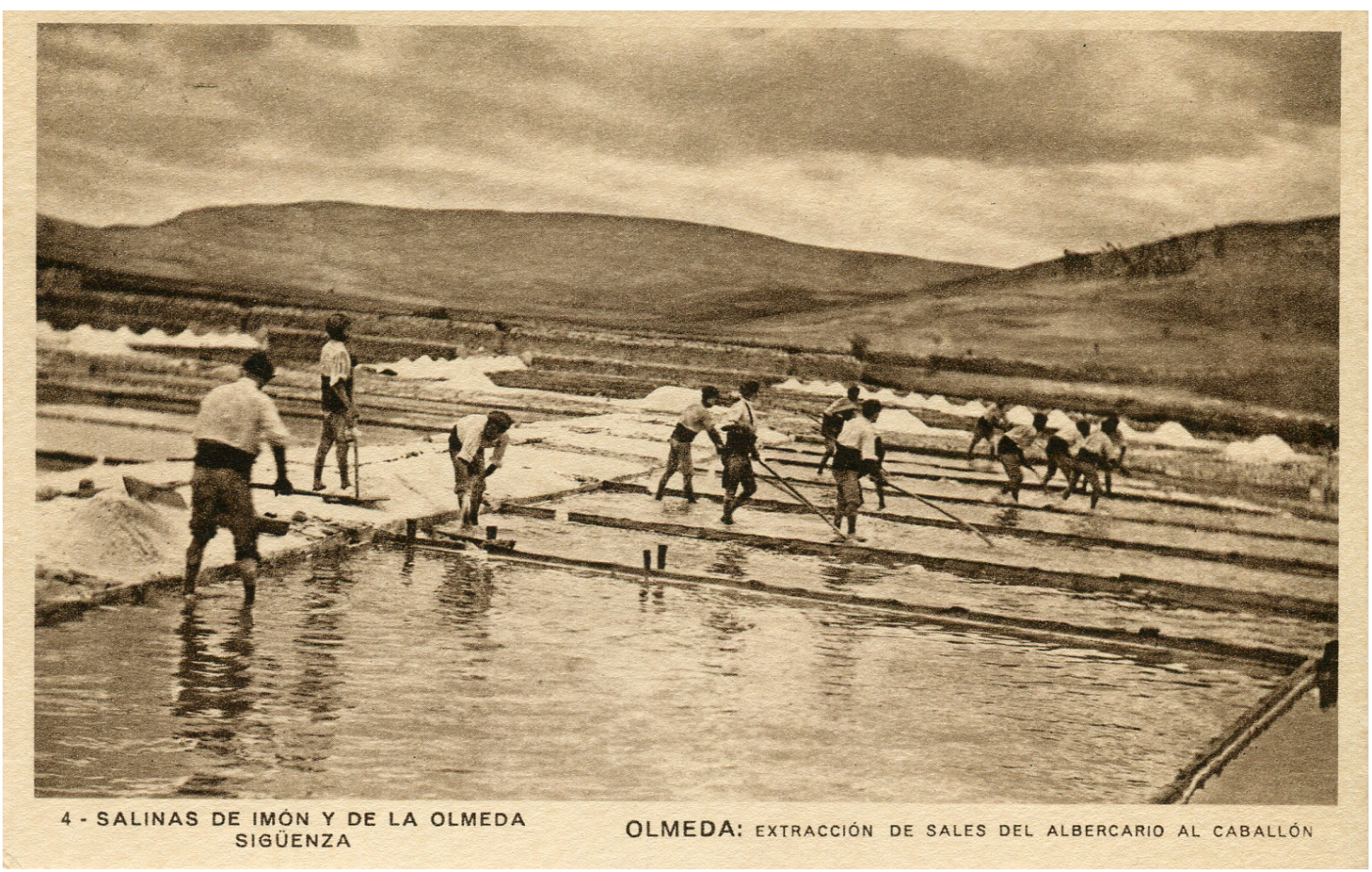

Fig. 10. "Campesinos de la sal" en una postal histórica de la Olmeda de Jadraque (ca. 19051930). Fuente: Centro de Estudios de Castilla-La Mancha, Tarjetas postales, Signatura: POS 3623

del valle en cuyas inmediaciones. En un radio de ca. $1 \mathrm{~km}$ alrededor de la laguna se localizan los asentamientos plenomedievales con materiales cerámicos andalusíes en superficie de Océn, Albalate y Torre de Océn, así como el castillo de Almalaff, que además de tener constatada una ocupación desde época califal tiene un topónimo de evidente relación con la explotación salinera (al-mallah en árabe significa la salina) (Retuerce, 1995, p. 110 y 113; Lázaro, 1995, p. 68; García-Contreras, 2016, p. 377; Batanero y Alcón, 2018). Además de la relación con las salinas de origen andalusí que marca ese topónimo de Almalaff que aparece ya en el fuero de Molina de 1142, apenas catorce años después de la conquista cristiana del territorio (Sancho, 1916, p. 65), hay que señalar que en la más temprana documentación medieval que hace referencia a esta zona, concretamente en 1191, se cita una salina que beneficiaba al monasterio de Óvila y que estaba situada próxima a Sotodosos, aldea que está al sur de la laguna de Océn (Minguella, 1910, p. 474).

\section{CONCLUSIONES}

Lo que hemos tratado de plasmar en estas líneas son algunas reflexiones sobre la explotación de la sal y la relación con el poblamiento en el norte y este de la provincia de Guadalajara, y en parte también el sur de Soria, durante la época andalusí. En esta búsqueda de la configuración de los paisajes andalusíes hemos partido de 
los condicionamientos geológicos e hidrológicos que tiene el poblamiento, y hemos atendido a las regulaciones que marcaron la producción y distribución de la sal, intentando en la medida de lo posible de aunar perspectivas sociales y ambientales. Evidentemente, necesitamos continuar avanzando, sobre todo con la participación de distintas técnicas y especialistas. Y sobre todo, estamos faltos de excavaciones arqueológicas, tanto en lugares de hábitat como en espacios de trabajo, que permitan dotar de densidad al conocimiento histórico de esta región, y de dinamicidad a esta imagen en exceso estática que hemos ofrecido. En cualquier caso, pensamos que sobre algunas conclusiones podemos ir reflexionando.

Debemos reconocer que los datos arqueológicos, aún cuando se combinan con la toponimia y las primeras referencias que aparecen en textos medievales, son poco consistentes. A ello debemos añadir la práctica inexistencia de documentación escrita específica sobre las salinas en general para todo al-Andalus (García-Contreras, 2011) y específicamente para las tierras de Guadalajara (García-Contreras, 2013). Por lo poco que sabemos, da la impresión que en un primer momento toda zona susceptible de ser explotada para la obtención de sal pasaba a ser propiedad de quien la trabajara, por derecho de vivificación similar al de los campos agrícolas (Camarero, 2004; Serrano 2010) ya que debido a su estacionalidad y la necesidad de trabajo para elaborar la materia prima era considerada una actividad eminentemente agrícola (Quesada, 1995; García-Contreras, 2011), no debiendo en nuestra opinión de incluirlo en una actividad propiamente minera (Echevarría, 2009). De su particular condición como "agricultura mineral", si se nos permite la expresión, da cuenta la existencia de contratos de arrendamiento y de aparcería entre particulares para la gestión y trabajo de las salinas al menos en el s. XII (Echevarría 2005 y 2010). Aunque no conocemos bien en manos de quién estaba la producción ni la distribución de la sal del norte y este de Guadalajara en época andalusí, varios datos explicados en este trabajo apuntan a un aprovechamiento directo por parte de las comunidades rurales de base campesina: la organización del poblamiento en sus inmediaciones, sin prácticamente estructuras que podamos relacionar directamente con el Estado andalusí ni tampoco estructuras defensivas salvo las torres de alquería y algunos asentamientos en altura; en segundo lugar la ausencia de referencias en la documentación escrita coetánea que solía marcar las propiedades relacionadas con explotaciones que generaban beneficios al poder estatal; en tercer lugar el repetido reparto de espacios en torno a las alquerías para combinar distintas actividades económicas agrícolas, ganaderas y salineras etc. Todos estos argumentos apuntan hacia este control directo por parte de quienes habitaban en el ámbito rural y no de poderes ajenos a él. Esto no debe entenderse en ningún caso como una pretendida horizontalidad social ni tendencia autárquica, toda vez que el campesinado en al-Andalus estuvo jerarquizado social y económicamente, además de dividido por categorías de género, con desigualdades que dieron lugar, o fueron consecuencia, del 
desarrollo de poderes locales. Pero sí apunta en esa dirección de la independencia productiva de gran parte del ámbito rural andalusí, siempre que mantuviese una relación fluida en el pago de impuestos al Estado, primero Omeya y luego Taifa. Cabe pensar, por lo tanto, en que esa explotación eminentemente campesina, que además fue estacional pues dependía del calor y la ausencia de lluvias para obtener la evaporación de la salmuera y la concentración del grano de sal, pudiera serlo en base a familias extensas, que es a lo que responde, por lo que sabemos, la organización social en el ámbito rural andalusí. Esto explicaría el tamaño y la localización de los asentamientos documentados en esas medias laderas, con las áreas de viviendas muy próximas a las áreas de explotación agrícola, ganadera y salina, lo que cambiará cuando estas salinas dejen de estar en manos directas del campesinado con posterioridad a la conquista castellana (García-Contreras, 2018b, 2019a). De todas formas, reconocemos que entramos aquí ya en el terreno de las hipótesis con la que seguir trabajando en el futuro. Éstas sólo podrán ser contrastadas o rebatidas cuando se acometan excavaciones en estos asentamientos rurales o se perfeccionen técnicas de análisis indirecto sobre el impacto de las explotaciones salineras, como por ejemplo cambios en el paisaje vegetal que se detecten en diagramas polínicos, toda vez que el estudio arqueológico directo de los centros productores de sal parece estar muy limitado cuando no directamente imposibilitado debido a reformas posteriores que han borrado la materialidad de las salinas de época andalusí.

\section{REFERENCIAS BIBLIOGRÁFICAS}

Almagro Gorbea, A. (1976). Las torres bereberes de la Marca Media. Aportaciones a su estudio. Cuadernos de la Alhambra, 12, 279-305.

AlONSO FERNÁNDEZ, J. (1978). La capacidad económica y poblacional del suelo en las comarcas serranas de Guadalajara, Wad-al-Hayara, 5, 237-249.

Alonso Ramos, J. A. (1988). "El Armallak". Génesis de un culto en Riba de Saélices (Guadalajara). Cuadernos de Etnología de Guadalajara, 4, 33-56.

Altimir Bolva, J. (1946). La sal Española y su legislación: 1252-1945. Madrid.

ARENAS Esteban, J. A. y Martínez NARAnjo, J. P. (1999). La explotación de sal durante la Edad del Hierro en el Sistema Ibérico. En: F. Burillo (ed.), IV Simposio sobre los Celtíberos. Economía (pp. 209-212). Zaragoza.

https://doi.org/10.30861/9781841711027

Ávila SeOANE, N. (2005). El proceso de señorialización de la Extremadura castellana: el ejemplo de la provincia de Guadalajara (siglos XII-XVIII). Tesis doctoral inédita. Madrid: Universidad Complutense de Madrid.

Batanero Nieto, A. y Alcón García, I. A. (2018). La torre de la laguna de la Hortezuela de Océn. En G. García-Contreras y L. Olmo (eds.): Arqueología Medieval en Guadalajara. Agua, paisaje y cultura material (pp. 233-248). Granada, Editorial Alhulia. 
Bermejo Crespo, J.L. y Muñoz López, K. (1996). La producción cerámica en el entorno del Henares durante los siglos IX y X. En Actas del V Encuentro de Historiadores del Valle del Henares, (pp. 79-86), Guadalajara: IMS-IEECCCEESS.

- (1999). Poblamiento y frontera en los Valles del Jarama y Henares en época islámica. En R. de Balbín y P. Bueno (eds.), II Congreso de Arqueología Peninsular, Zamora, del 24 al 27 de septiembre de 1996 (vol. IV, pp. 555-560), Alcalá de Henares: Fundación Rei Afonso Henriques.

BlázQuez Garbajosa, A. (1985). La reconquista de Sigüenza y su significación geopolítica regional. Wad-al-Hayara, 12, 35-42.

Bueno M. (2009). El papel de la Orden de Calatrava en la reorganización del espacio soriano en el siglo XIII. En: El nacimiento de la Orden de Calatrava. Primeros tiempos de expansión (siglos XII-XIII) (pp. 345-275). Ciudad Real.

- (2012). Más allá del territorio, tradiciones en el entorno del Jalón. En B. Arizaga et al. (eds), Mundos medievales: espacios, sociedades y poder. Homenaje al profesor José Ángel García de Cortázar y Ruiz de Aguirre (vol. 1, pp. 413-425). Cantabria.

- (2015). Power and rural communities in the Banû Salîm area (eighth-eleventh centuries): Peasant and frontier landscapes as social construction. En: F. Sabaté y A. Fábregas (eds), Power and rural communities in Al-Andalus: Ideological and material representations (pp. 17-51). Turnhout: Brepols.

Camarero Castellano, I. (2004). Las labores vivificadoras como medio de adquisición de la propiedad de tierras muertas. Ciencias de la Naturaleza en alAndalus. Textos y Estudios, VII, 179-193.

Cantera Burgos, F. y Carrete Parrondo, C. (1973). Las juderías medievales en la provincia de Guadalajara. Sefarad, 33-2, 260-323.

Carrasco Vayá, J.-F., y Hueso KortekaAs, K. (2008). Los paisajes ibéricos de la sal. 1. Las salinas de interior. Guadalajara.

Chavarría VArgas, J. A. (1997). El valle del Tiétar en la Marca Media de Al-Andalus (Al-Tagr Al Awsat). Trasierra: boletín de la Sociedad de Estudios del Valle del Tiétar, 2, 95-112.

Checa Herraiz, J. (2014). Dinámicas de ocupación y transformación del territorio medieval en el Alto Tajo (Guadalajara). Arqueología y Prehistoria del Interior Peninsular, 1, 64-85.

Clemente Ramos, J. (2008). Agrosistemas hispanocristianos: el secano (Corona de Castilla, siglos X-XV). En: De la Iglesia Duarte, J. I. (ed.), Cristiandad e Islam en la Edad Media Hispana. XVIII Semana de Estudios Medievales. Nájera, del 30 de julio al 3 de agosto de 2007 (pp. 239-270). Logroño.

Colón, H. (1988). Descripción y Cosmografía de Hernando Colón (1517): manuscrito de la Biblioteca Colombina. Sevilla. 
CORTÉS RUIZ, M ${ }^{A}$ E. (2000). Articulación jurisdiccional y estructura socioeconómica en la comarca de Molina de Aragón a lo largo de la Baja Edad Media: 6 volúmenes. Tesis doctoral inédita. Universidad Complutense de Madrid.

Cruz García, O. (1989). Norias de tradición mudéjar en las salinas de Imón (Guadalajara). Revista de Folklore, 107, 147-166.

De Felipe, H. (1997). Identidad y onomástica de los bereberes de al-Andalus, Madrid: CSIC.

De la Granja, F. (1966). La Marca Superior en la obra de al-Udri. Estudios de la Edad Media de la Corona de Aragón, VIII, 447-545.

DONDERIS GuAstavino, A. (2008). Historia de la sal y las salinas: fuentes para su estudio en el archivo municipal de Sigüenza. En: Morère, N. (ed.), Las salinas y la sal de interior en la Historia: economía, medio ambiente y sociedad (pp. 31-44). Madrid.

ECHEVARRÍA ARSUAGA, A. (2005). La propiedad de los yacimientos mineros andalusíes en el siglo XII. En: O. Puche y M. Ayarzagüena (eds.), Minería y metalurgia históricas en el sudoeste europeo (pp. 345-350), Madrid.

- (2009). La minería de la sal en el norte de la Meseta: ¿una redefinición de los espacios productivos rurales?. En: I. Martín Viso (de), ¿Tiempos oscuros? Territorio y sociedad en el centro de la Península Ibérica (siglos VII-X) (pp. 181202). Salamanca: Sílex.

- (2010). Explotación y mano de obra en las minas y salinas de al-Andalus. Espacio, Tiempo y Forma. Serie III Historia Medieval, 23, 55-74.

EsPEJO, C. (1918-1919). La renta de las salinas hasta la muerte de Felipe II. Revista de Archivos, Bibliotecas y Museos, XXXVIII, 47-63 y 220-233, XXXIX, 37-52 y XL, 91-114.

Estepa Díez, C. (2006). Frontera, nobleza y señoríos en Castilla: el señorío de Molina (siglos XII-XIII). Studia historica. Historia Medieval, 24, 15-86.

Fabián Fabián, A. P. (2012). La Reconquista de Molina. Revisión histórica. Albacete. Fidalgo Hijano, C. (1987). La Transformación humana del paisaje en la Serranía de Atienza, Madrid.

García-Contreras Ruiz, G. (2011). Production and use of salt in al-Andalus. State of the art and perspective for its study, En: J. Klápště y P. Sommer, (eds.), Food in the Medieval Rural Environment. Processing, Storage, Distribution of Food. Ruralia VIII: (pp. 31-43). Turnhout (Belgium): Brepols Publishers. https://doi. org/10.1484/M.RURALIA-EB.1.100154

- (2012). Hydrogeological conditions in the medieval settlement pattern in the Northeast Valleys of Guadalajara (Spain). En: F. Bertoncello y F. Braemer (eds.), Variabilités environnementales, mutations sociales. Natures, intensités, échelles et temporalités des changements (pp. 281-291). Antibes. 
- (2013). Et cum salinis. Aproximación documental a las salinas del norte de Guadalajara en los siglos XII-XIII. En: Villar, S. (ed.), Sal, agricultura y ganadería: la formación de los paisajes rurales en la Edad Media (pp. 169-204). Palma de Mallorca: Vessants

- (2015). Châteaux et paysans dans le nord de Guadalajara: réflexions sur l'étude du peuplement rural à la frontière d'al-Andalus. En: S. Gilotte y E. Voguet (eds.), Terroirs d'Al-Andalus et du Maghreb médiéval VIIIe-XVe siècle. Peuplements, ressources et sainteté: (pp. 51-82). Saint-Denis: ed. Bouchène.

- (2016). Paesaggi del sale nei confini d'al-Andalus: riflessioni sul settore centroorientale della Penisola Iberica fra VIII e XII secolo. Archeologia Medievale, XLIII, 363-382.

- (2018a). Poblamiento rural y gestión del agua en la Marca Media de al-Andalus: El 'Val de la Riva' en el Alto Henares. En: G. García-Contreras y L. Olmo (eds.): Arqueología Medieval en Guadalajara. Agua, paisaje y cultura material (pp. 197230). Granada: Editorial Alhulia.

- (2018b). Feudalización y cambio ecológico en el sector oriental de la Extremadura castellana: poblamiento y paisaje en los territorios de Atienza, Sigüenza y Molina (siglos XI-XIII). En: J, Torró y E. Guinot (eds.), Trigo y Ovejas. El impacto de las conquistas en los paisajes de al-Andalus (siglos XI-XVI) (pp. 51-76). Valencia.

- (2019a). 'Ay malos pasos et tremedales'. El agua como condicionante del poblamiento medieval del señorío episcopal de Sigüenza (Guadalajara). Riparia, 5, 167-209. https://doi.org/10.25267/Riparia.2019.v5.07

- (2019b). Los Banu Salim y otros linajes beréberes en el centro de la Península Ibérica. En: AA.VV. La Granada Zirí y el Universo Beréber. Catálogo exposición Beréberes Alhambra (pp. 72-79). Granada.

- (2020). Primera aproximación a la tipología cerámica andalusí del noreste de Guadalajara: materiales de la prospección de los valles del Salado y el Alto Henares. En: A. García Porras (ed), Estudios de cerámica medieval y postmedieval (pp. 165-230). Granada: Alhulia.

- (2021). 'E por do suele e debe andar las dichas salinas de Atienza'. El comercio de la sal del nordeste de Guadalajara en época medieval. En: D. Boisseuil. C. Rico y S. Gelichi (eds.), Le marché des matières premières dans l'Antiquité et au Moyen Âge (pp. 405-422). Roma: Collection de L'École française de Rome.

García luján, J. A. (1981). Cartulario del monasterio de Santa María de Huerta, Zaragoza.

GARCÍA Oliva, M. D. (2007). Un espacio sin poder: la transierra extremeña durante la época musulmana. Studia histórica. Historia Medieval, 25, 89-120.

García-QuintanA, A. (2008). Geología y paisajes de Guadalajara. En: A. Calonge y M. Rodríguez (eds.), Geología de Guadalajara (pp. 15-71). Guadalajara. 
García-Soto MateOS, E. (2005). La comarca seguntina en época islámica, siglos VIII-XII. Anales Seguntinos, 21, 7-37.

- (2006). Estudio de algunos complejos salineros contemporáneos de las comarcas de Atienza y Sigüenza: Tordelrábano, Paredes de Sigüenza, Rienda, Riba de Santiuste y Valdealmendras-Torre de Valdealmendras. Anales Seguntinos, 22, 13-25.

García-Soto Mateos, E. y Ferrero Ros, S. (2006). Excavaciones en las salinas de San Juan (Saélices de la sal, Guadalajara). Boletín de la Asociación de Amigos del Museo de Guadalajara, 1, 81-112.

- (2007). Estudio de algunos complejos salineros contemporáneos de las comarcas de Atienza y Sigüenza: Cercadillo-Santamera, Bujalcayado-La Olmeda de Jadraque, El Atance y Cirueches. Anales Seguntinos, 23, 85-120.

García-Soto Mateos, E., Ferrero Ros, S. y Guillén Álvarez de Sotomayor, A. (2004). Los Casares: un poblado hispanomusulmán en las serranías del norte de la provincia de Guadalajara. En: Investigaciones arqueológicas en Castilla-La Mancha, 1996-2002 (pp. 395-408). Toledo.

GiLOTTE, S. (2008). Al margen del poder. Aproximación arqueológica al medio rural extremeño (ss. VIII-XIII). En F. Sabaté y J. Brufal (eds.), Arqueologia Medieval II: La transformació de la frontera medieval musulmana (pp. 53-79), Lleida: Pagés editors.

Gismera Velasco, T. (2016). Historia de las salinas de Tierra de Atienza: Imón, La Olmeda, Almallá, Saélices, Medinaceli y Guadalajara. Guadalajara.

GonzÁlez GonzÁlez, J. (1960). El Reino de Castilla en la época de Alfonso VIII. Madrid.

Gual Camarena, M. (1965). Para un mapa de la sal hispana en la Edad Media. En: Maluquer de Motes, J. (ed.), Homenaje a Jaime Vicens Vives (pp. 483-498). Barcelona.

Guinot Rodríguez, E. (2008). Agrosistemas del mundo andalusí: criterios de construcción de los paisajes irrigados. En: De la Iglesia Duarte, J. I. (ed.), Cristiandad e Islam en la Edad Media Hispana. XVIII Semana de Estudios Medievales. Nájera, del 30 de julio al 3 de agosto de 2007 (pp. 209-238). Logroño.

HALDON, J. (1998). El modo de producción tributario: concepto, alcance y explicación. Hispania, LVIII/3, 200, 795-822.

HeRnANDO COSTA, S. (1977). Aspectos paleogeográficos del «Keuper» en el borde SW de la rama castellana de la Cordillera Ibérica (Provincias de Segovia, Soria y Guadalajara). Cuadernos de Geología Ibérica, 4, 385-398.

Herrera CASAdO, A. (1985). La Marca Media de al-Andalus en tierras de Guadalajara. Wad al-Hayara, 12, 9-26.

JimÉNEZ GADEA, J. (1995). Los asentamientos beréberes en al-Andalus. En J.I. De la Iglesia (de.) V Semana de estudios medievales: Nájera,1 al 15 de agosto de 1994 (pp. 209-215), Nájera: Instituto de Estudios Riojanos. 
Ladero Quesada, M. Á. (1987). La renta de la sal en la Corona de Castilla (siglos XIII-XVI). En: Homenaje al profesor Juan Torres Fontes (pp. 821-838). Murcia.

LÁzAro, I. (1995). La época islámica en la comarca de Molina de Aragón, Universidad Complutense de Madrid (Trabajo Fin de Carrera inédito).

Layna Serrano, F. (1945). Historia de la villa de Atienza. Madrid (reed. 2004, Guadalajara).

LizoAin Garrido, J. M. (1985). Documentación del monasterio de las Huelgas de Burgos (1116-1230). Burgos.

LÓPEZ DE LOS MOZOS, J. R. (2014). El ocaso de las salinas de interior en la provincia de Guadalajara. Revista de Folklore, 391, 26-39.

López SÁez, J. A., López García, P. y Martín SÁnchez, M. (2002). Palaeoecology and Holocene environmental change from a saline lake in South-West Spain: protohistorical and prehistorical vegetation in Cádiz Bay. Quaternary International, 93-94, 197-206. https://doi.org/10.1016/S1040-6182(02)00018-6

lópez Sáez, J. A., Abel SchaAd, D., Iriarte, E., Alba Sánchez, F., Pérez díaz, S., Guerra Doce, E., Delibes de Castro, G. y Abarquero Moras, F. J. (2017). Una perspectiva paleoambiental de la explotación de la sal en las Lagunas de Villafáfila (Tierra de Campos, Zamora). Cuaternario y Geomorfología, 31 (1-2), 73-104. https://doi.org/10.17735/cyg.v3lil-2.54255

Malpica Cuello, A. (2002). Las salinas en la frontera del reino nazarí de Granada y su papel en la economía ganadera castellana. Thesis. Wissenschaftliche Zietschrift der Bauhaus-Universität Weimar, 48 (4/5), 236-246.

- (2008). Análisis de las salinas medievales desde la Arqueología del Paisaje. En: Morère Molinero, N. (ed.), Las salinas y la sal de interior en la Historia: economía, medio ambiente y sociedad (vol. 1, pp. 469-498). Madrid.

- (2012). El agua en la agricultura. Agroecosistemas y ecosistemas en la economía rural andalusí. Vínculos de Historia, 1, 31-44.

- (2015). Le trasformazioni agricole e l'avanzata cristiana nella penisola iberica. En: I paesaggi agrari d'Europa (secoli XIII-XV): Ventiquattresimo Convegno Internazionale di Studi (Pistoia, maggio 2013) (pp. 101-125). Roma.

- (2018). La arqueología del paisaje medieval. Formaciones sociales y agroecosistemas en la Península Ibérica. En: G. García-Contreras Ruiz y L. Olmo Enciso (eds.), Arqueología Medieval en Guadalajara. Agua, paisaje y Cultura Material (pp. 2341). Granada: Editorial Alhulia.

Malpica Cuello, A., Morère Molinero, N., Jiménez Gujurro, J. y GarcíaContreras Ruiz, G. (2011). Paisajes de la sal en la Meseta castellana desde la Prehistoria a la Edad Media: el valle del Salado (Guadalajara). En: M. Jiménez Puertas y G. García-Contreras Ruiz (eds.), Paisajes históricos y Arqueología Medieval (pp. 233-276). Granada: Editorial Alhulia. 
Malpica Cuello, A., Villar mañas, S. y García-Contreras Ruiz, G. (2013). Sal y ganadería en el Reino de Granada (siglos XIII-XV), un proyecto de investigación sobre dos importantes actividades económicas en época nazarí. Debates de Arqueología Medieval, 3, 375-390.

Malpica Cuello, A., Villar mañas, S., García-Contreras Ruiz, G. y Martínez VÁZQUEZ, L. (2015). In search of the shepherds. Archaeological and historical perspectives for the study of salt and animal husbandry in the north of the kingdom of Granada. En: F. Carrer y V. Gheller (eds.), Invisible Cultures. Historical and Archaeological Perspectives (pp. 176-195). Cambridge Scholars Publishing.

MANZANO Moreno, E. 1991. La frontera de al-Andalus en época de los Omeyas. Madrid: CSIC.

- (1998). Relaciones sociales en sociedades precapitalistas: una crítica al concepto de modo de producción tributario. Hispania, LVIII/3, 200, 881-913.

Meniz Márquez, C. (1988). Bosquejo histórico del complejo salinero de Guadalajara durante el estanco de la sal (1564-1870). En: Actas del I Encuentro de Historiadores del Valle del Henares (pp. 513-521). Guadalajara.

Minguella y Arnedo, T. (1910). Historia de la diócesis de Sigüenza y sus obispos. Tomo I. Madrid.

- (1912). Historia de la diócesis de Sigüenza y sus obispos. Tomo II. Madrid.

Muñoz y ROMERO, T. (1847). Colección de fueros municipales y cartas pueblas de los reinos de Castilla, León, Corona de Aragón y Navarra. Madrid.

Morère Molinero, N. (1983). Carta arqueológica de la región seguntina. Madrid: Institución Provincial de Cultura "Marqués de Santillana"

NúÑEZ MARTí, P. (2015). Arquitectura y construcción, paisaje y territorio: los refugios de la Cuenca Alta del río Tajo. Tesis doctoral inédita, Universidad Politécnica de Madrid.

Olmo Enciso, L. (2002). Arqueología Medieval en Guadalajara. Un estado de la cuestión. En: E. García-Soto y M. Á. García Valero (eds.), Actas del primer simposio de Arqueología de Guadalajara. Homenaje a Encarnación Cabré Herreros (pp. 467500). Guadalajara.

- (2011). De Celtiberia a Šantabariyya: La gestación del espacio y el proceso de formación de la sociedad andalusí (ss. VIII-IX). En: 711. Arqueología e Historia entre dos mundos. Zona Arqueológica, 15/2, 39-64.

Ortega Ortega, J. M. y Arenas Esteban, J. A. (2018). Una suplantación social del espacio. Arqueologías de la conquista feudal en la región de Molina de Aragón. En: G. García-Contreras y L. Olmo (eds.): Arqueología Medieval en Guadalajara. Agua, paisaje y cultura material (pp. 337-373). Granada, Editorial Alhulia.

Ortego Rico, P. (2013). Las salinas de Atienza, Medinaceli y Molina de Aragón en la Baja Edad Media: propiedad, comercio y fiscalidad. Historia, Instituciones, Documentos, 40, 207-249. https://doi.org/10.12795/hid.2013.i40.07 
Ortiz Carrascosa, O. y SACristán TORdesillas, M. (2001). Arquitectura rural en la serranía de Guadalajara. Las parideras y los casillos. Revista de folklore, 247, 28-32

Pardo Rodríguez, M. L. (1993). Documentación del condado de Medinaceli (13681454). Soria.

PAstor De TOgnery, R. (1963). La sal en Castilla y León. Un problema de la alimentación y del trabajo y una política fiscal (siglos X-XIII). Cuadernos de Historia de España, XXXVII-XXXVIII, 42-87.

Pavón Maldonado, B. (1984). Guadalajara medieval. Arte y arqueología árabe y mudéjar. Madrid: CSIC.

Plata Montero, A. (2003). La aplicación de la arqueología de la arquitectura a un complejo productivo. El valle salado de Salinas de Añana (Álava). Arqueología de la Arquitectura, 2, 241-248. https://doi.org/10.3989/arq.arqt.2003.53

- (2006). El ciclo productivo de la sal y las salinas reales a mediados del siglo XIX. Vitoria-Gasteiz.

QUESADA QUESADA, T. (1995). El agua salada y las salinas. En: El agua en la agricultura de al-Andalus (pp. 57-80). Barcelona-Granada.

RetUerCe Velasco, M. (1994). Carta arqueológica de la Meseta Andalusí. El referente cerámico. Boletín de Arqueología Medieval, 8, 7-109.

- (1995). Arqueología y poblamiento en la Meseta Andalusí: El referente cerámico. En: J. I. De la Iglesia (ed.), V Semana de Estudios Medievales de Nájera (pp. 87 124). La Rioja.

Rodríguez Bañuelos, I. (2015). El Censo de la Sal, 1631. Madrid.

RodrígueZ GONZÁlEZ, E. (2012). Estudio arquitectónico y etnográfico de los chozones y parideras sabineras del Parque Natural del Alto Tajo. Cuadernos de Etnología de Guadalajara, 43-44, 145-166.

RODRÍGUEZ RodríGUEZ, E. (2000). Historia de las explotaciones salinas en las lagunas de Villafáfila, Zamora.

SAnCho IzQuierdo, M. (1916). El Fuero de Molina de Aragón. Madrid.

SERrano RuANo, D. (2010). Minas en colecciones de fetuas y casos jurídicos del Occidente islámico (ss. XII-XVI d.C.): el problema de la propiedad de los yacimientos mineros. Espacio, Tiempo y Forma-Historia Medieval, 23, 85-203. https://doi.org/10.5944/etfiii.23.2010.1661

Trallero Sanz, A., Arroyo San José, J. y Martínez Señor, V. (2003). Las salinas de la Comarca de Atienza. Guadalajara.

WiCKHAM, Ch. (1989). La otra transición: del mundo antiguo al feudalismo. Studia Historia. $H^{a}$ Medieval, VII. 7-35.

ZOZAYA, J. (1991). Recientes estudios sobre la Arqueología andalusí: la frontera media. Aragón en la Edad Media, 9, 371-388.

- (2004). Asentamientos islámicos en la región de Madrid. En A. Turina, S. Quero y A. Pérez (eds.) Testimonios del Madrid Medieval. El Madrid Musulmán (pp. 4379). Madrid: Museo de San Isidro. 